\title{
THREE-DIMENSIONAL SURVEY OF GUATTARI CAVE WITH TRADITIONAL AND MOBILE PHONE CAMERAS
}

\author{
L. Alessandri ${ }^{1}$, V. Baiocchi ${ }^{2}$, S. Del Pizzo ${ }^{3}$, F. Di Ciaccio ${ }^{3}$, M. Onori ${ }^{2}$, M. F. Rolfo ${ }^{4}$, S. Troisi ${ }^{3}$ \\ ${ }^{1}$ University of Groningen, GIA, Poststraat 6, 9712ER, Groningen (The Netherlands) - 1.alessandri@rug.nl \\ ${ }^{2}$ Sapienza University of Rome, DICEA, Via Eudossiana 18, 00184 Rome (Italy) - valerio.baiocchi@ uniroma1.it \\ ${ }^{3}$ Parthenope University of Naples, Centro Direzionale Isola C4, Naples (Italy) - (silvio.delpizzo, fabiana.diciaccio, \\ salvatore.troisi)@uniparthenope.it \\ ${ }^{4}$ University of Tor Vergata, Department of History, Culture and Society, Via Columbia 1, 00133 Rome (Italy) - rolfo@ uniroma2.it
}

\section{Commission II}

KEY WORDS: Photogrammetry, Structure from Motion, Cultural Heritage, 3D modeling, Georeferencing, Neandertal, Pleistocene

\begin{abstract}
:
Sometimes, the georeferencing of a cave in the global reference system can be challenging. Some difficulties may arise when narrow passages do not allow the use of classical topographic equipment or a terrestrial laser scanner. In these specific cases, the surveyor can employ a visual-based approach to produce both the followed path and the 3D model of the hypogeum. The report we are presenting is the result of a survey in the Guattari cave carried out using images taken by a Huawei P9 mobile phone and a Nikon D800E camera with a $16 \mathrm{~mm}$ fisheye lens. Several targets were measured in order to contain the deformation of the models. Three GCPs located just outside the cave have been used to georeference the models. The data have been acquired by a double frequency GNSS receiver in static session mode. The comparison between the two models shows a substantial concordance only in the area outside the cave where the GCPs were measured. In the innermost areas, the two models differ by as much as two meters.
\end{abstract}

\section{INTRODUCTION}

The mapping of a cave can be attained by means of topographic surveying methods, generally performed with a total station. Unfortunately, sometimes such equipment cannot be used in very narrow spaces. A terrestrial laser scanner (LS) can be used when a 3D model is also required. However, LS is subject to similar limitations (Angelini et al., 2017; Stocchi et al., 2017). In such harsh environments, only SLAM (Simultaneous Localization and Mapping) techniques can be used. In fact, the scientific literature about the performances of these methodologies under different severe environments is increasing (Eyre et al., 2016; Mandelli et al., 2017; Sammartano et al., 2018).

Handheld or by otherwise portable scanners can be deployed to survey narrow environments, such as tunnels, mines and caves but this instrumentation is still too expensive.

On the other hand, the use of photogrammetric methodology, in particular the SfM (Structure from Motion) algorithms, has proven remarkable robustness and versatility in narrow environments, particularly when fast measurements are necessary and very high precision is not required.

In the papers by Troisi et al. (2017), Perfetti et al., (2017) and Alessandri et al. (2019), the mapping and the modeling of hypogea have been attained by the use of a camera equipped with fisheye lens. The latter is suggested when the length of the environment prevails on the other two dimensions (e.g. very narrow tunnels).

Image-based 3D reconstruction methods using mobile devices have been used in research and apps for this purpose have begun appearing in the app stores for smart devices (Nocerino et al., 2017; Chikatsu et al., 2009; Fritsch et al., 2015).

In this paper, we describe the survey of the Guattari cave, simultaneously performed with both a traditional and a smartphone camera. The differences between the two models will be outlined and discussed.

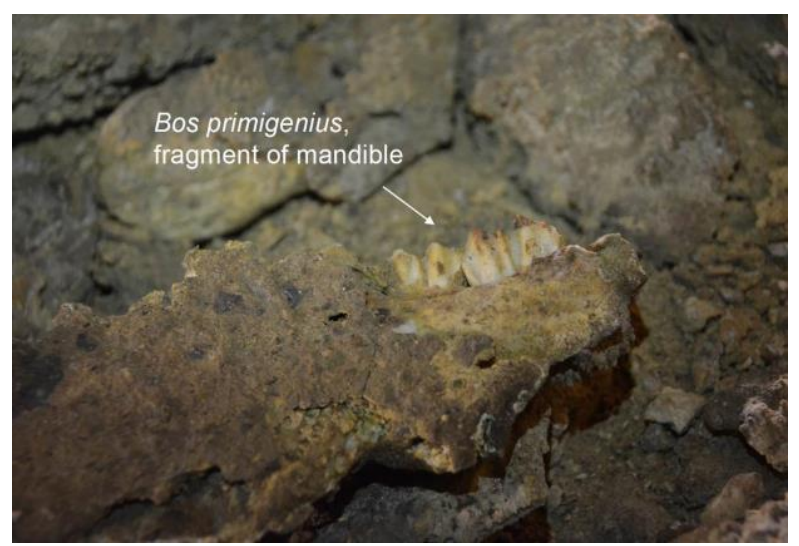

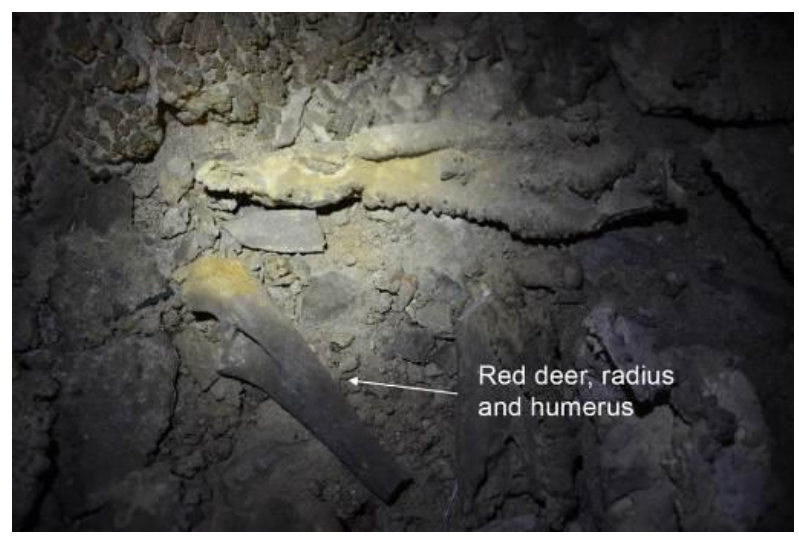

Figure 1. Some macromammals remains on the cave surface 


\section{SURVEY SETUP}

\subsection{Site description and issues}

The Guattari cave is located at the eastern side of the Morrone mountain, which is part of the calcareous Circeo mountain ridge. It is one of the most important natural caves of Italy, due to its late Pleistocene deposit and the hominin remains. The cave was discovered by chance in 1939. The surface of the deposit was characterized by abundant Pleistocene fauna (fig. 1 and 2) and a Neandertal skull was immediately noticed. Thereafter, the deposit was further investigated until the 1950s and two different hominin mandibles, probably belonging to different individuals, were also recovered (Blanc et al. 1953).

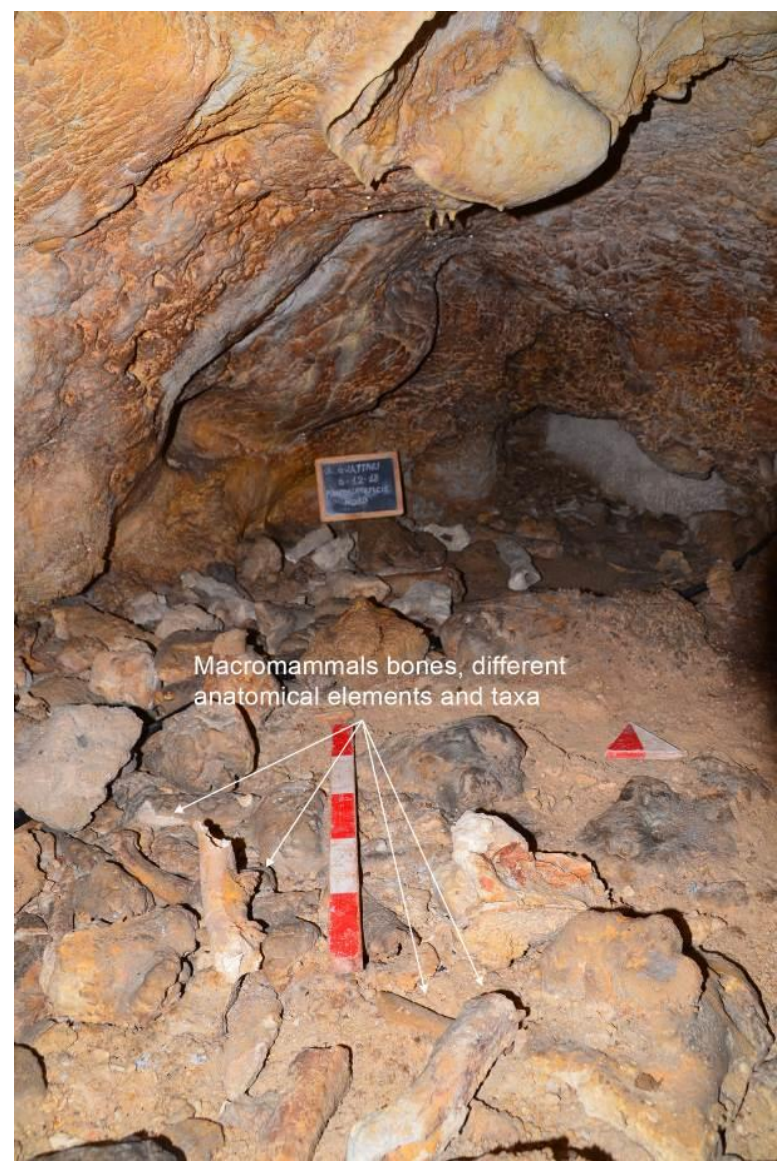

Figure 2. Some macromammals remains on the cave surface

Mousterian lithic industry and fauna were recovered. However, just from the beginning, the skull attracted a great deal of attention. In fact, when A. Guattari entered the cave for the first time, the skull was lying inside a stone circle, with the foramen magnum pointing upwards. The foramen magnum had also been clearly and intentionally widened. These data have been variously interpreted. The initial hypothesis was that both the context, inside the stone circle, the isolated nature of the specimen and the enlarged foramen were the results of Neandertal ritual cannibalism (Blanc 1961). Differently, some other scholars pointed out that the damage patterns were not unambiguously man-made and they were consistent with carnivore activity. Nonetheless, the presence of numerous hyena coprolites, the toothmarks, element and element portion representation of the bone assemblage all indicate that the cave was a hyena den (White, Toth, 1991).
In 2019, for the 80th anniversary of the cave discovery, the Soprintendenza Archeologia, Belle Arti e Paesaggio per le Province di Frosinone, Latina e Rieti has undertaken a series of initiatives to take stock of all the previous knowledge and to plan future studies. At the moment, the deposit origin and its internal chronological sequence are not sufficiently clear. In fact, few radiometric analyses have been done so far to precisely date the skull. Schwarcz and colleagues (1991) dated some calcite samples from the surface (U-series) at about $50 \mathrm{Ky} \mathrm{BP}$. Some other dates between 107.4 $\pm 16 \mathrm{KY}$ BP (layer 4) and 56.8 $\pm 4.8 \mathrm{KY}$ BP (surface) have been obtained by ESR (Electron Spin Resonance) method. The development of new absolute dating techniques (U-Th) and some discrepancies in the layer sequences suggested a critical review of both. The revised chronology will also take into account the geoarchaeological data coming from the reconstruction of the Latium shorelines between MIS 9 and MIS 5 (Marra et al. 2018).

In order to link the absolute heights of the entire layer sequence with the contemporary and reconstructed sea levels, a 3D model became advisable.

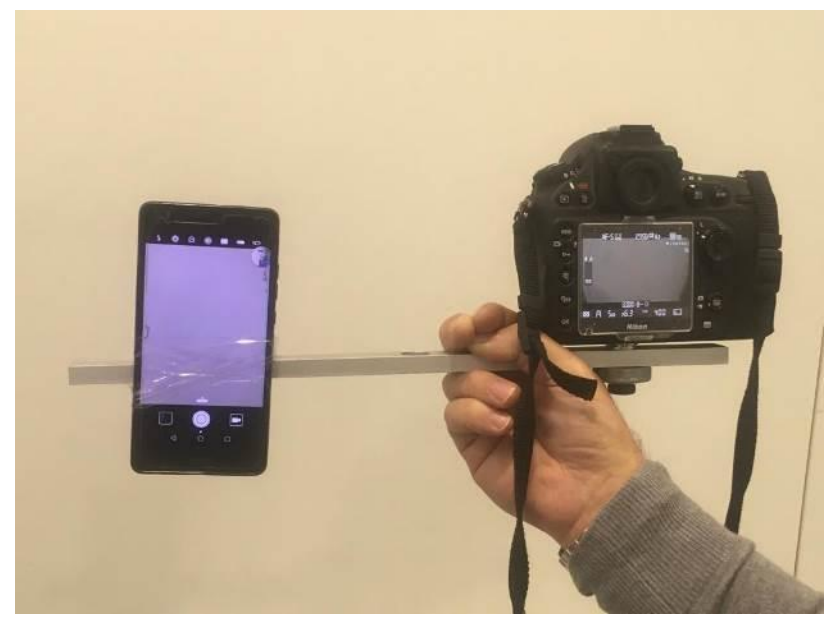

Figure 3. The handcrafted photogrammetric system used for the survey.

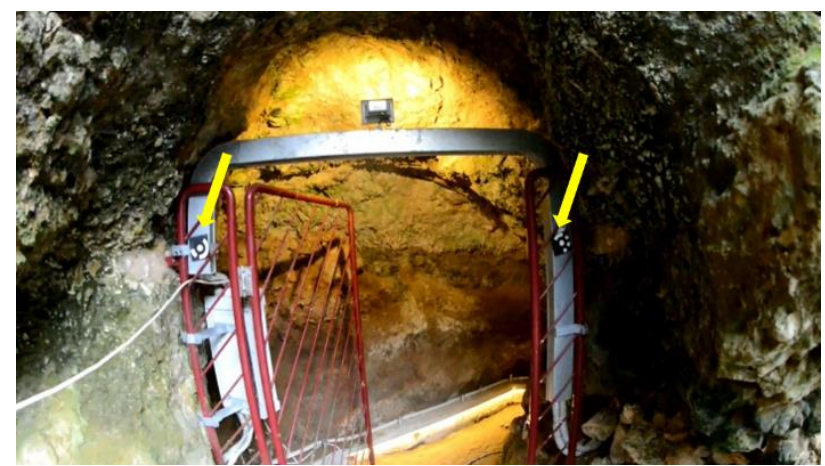

Figure 4 . The current entrance of the cave and the targets used as scale constraints.

\subsection{GNSS setup}

In order to georeference the 3D model generated by the $\mathrm{SfM}$ procedure, at least three Ground Control Points (GCP) belonging to the same point cloud must be known in the global reference system. This allows a 3D Helmert transformation with some degree of redundancy. Three GCPs outside the cave were stationed with tripods, the antenna of a Topcon Legacy-E doublefrequency GNSS receiver was then placed. Such antenna, being clearly visible, allowed easy collimation with the images taken 
by the camera used for the photogrammetric survey. The GNSS receiver stationed for about 40 minutes on each of the three points. A virtual reference station (VRS) was purposely calculated by the Lazio geodetic network management system. The latter is based on Leica's spiderweb software and framed in the ETRF2000- RDN2008 (EPSG: 7792). The VRS was created using FOND as the master station and FOND, LTNA, FROS, PONZ, VTEN, CASS, ARDE, VIVA and ROUN as auxiliary stations (Fig. 5). The resulting baselines were obviously very short and they were calculated with RTKLIB ver. 2.4.2. The heights of the antennas and accordingly of the point clouds are referred to the geoid. The transformation from the ellipsoidal heights was performed using the geoid model ITALGEO2005.

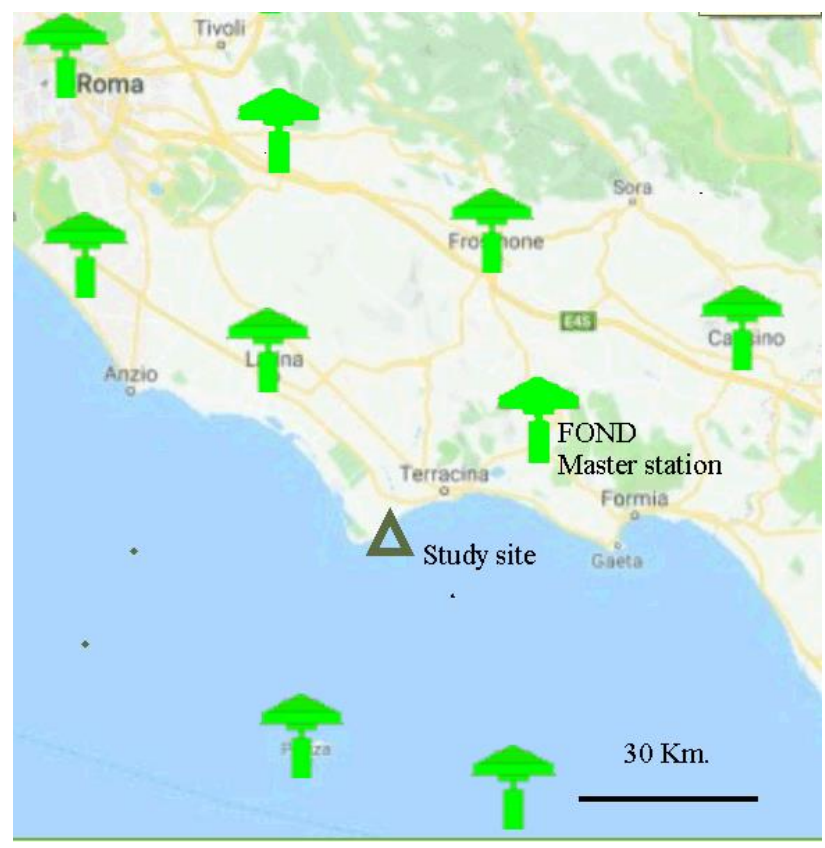

Figure 5. The study site and the permanent stations used to process the virtual station; from gnss-regionelazio.dyndns.org, redesigned.

\subsection{Photogrammetric setup}

The survey was carried out using a handcrafted system consisting of a $25 \mathrm{~cm}$ bar holding a Huawei P9 mobile phone and a Nikon D800E camera with a $16 \mathrm{~mm}$ fisheye lens (figure 3 ). Both were set in video mode and the recording was made in standard HD (High Definition) 1080p (60 fps) for the first camera and in $1280 \times 720$ format at $30 \mathrm{fps}$ for the second one.

Before starting the acquisition, several targets were positioned both at the entrance and inside the cave. Their mutual distances were then measured to get the data to constrain the deformations of the models. The recording phase started in the area just outside the cave, where three targets were positioned to identify the GCPs, then moved inside. The entire registration was performed with very slow movements to avoid unexpected light variations, even if the ISO sensitivity parameter, characteristic of every digital camera, allowed the automatic adjustment of the brightness gradient.

Since the light sources were fixed, some problems arose due to the shadows projected on the walls, especially when the operator was walking near a strong light behind his back. However, this only resulted in a color variation limited to the specific sections of the models.
The total acquisition took less than ten minutes and resulted in a simple video showing the surrounding area of the 170-meter round-trip route followed by the operator.

The attained videos were processed using a classical procedure employed in 3D image-based modeling by sampling a frame every $1 / 3$ seconds.

\section{DATA PROCESSING AND RESULTS}

\subsection{Processing}

We chose an easy procedure for the camera calibration, also suitable for inexperienced users: the self-calibration indicated as "on the job". This procedure is not always suitable to correctly compute the interior orientation parameters. Indeed, a weak geometry of the network camera frame and the lack of ground control points could provide results with low accuracy and reliability (Nocerino et al., 2014).

Using the Agisoft Metashape 1.5.0 software, more than 3000 oriented images have been processed to obtain two 3D models, one per camera. These photogrammetric models have been scaled and georeferenced using the 3 GCPs placed outside the cave and four scale constraints based on the distances measured between some targets. The latter had already been positioned in the cave in the first phase of the survey.

The total errors on the GCPs are different in the two models. The Huawei camera gave very low errors, with a mean of $2 \mathrm{~cm}$ and a maximum of less than $3 \mathrm{~cm}$, while the error obtained by the Nikon camera was 7 times higher, with a mean of $14 \mathrm{~cm}$ and a maximum of $18 \mathrm{~cm}$. A similar difference has been observed for the errors on the scale constraints: table 1 shows the values obtained for the four pairs of targets used in the process.

Table 1. Comparison of errors on scale constraints

\begin{tabular}{|l|l|l|l|}
\hline $\begin{array}{l}\text { Target } \\
\text { pair }\end{array}$ & $\begin{array}{l}\text { Distance } \\
(\mathrm{m})\end{array}$ & $\begin{array}{l}\text { Error Huawei } \\
(\mathrm{mm})\end{array}$ & $\begin{array}{l}\text { Error Nikon } \\
(\mathrm{mm})\end{array}$ \\
\hline $28-48$ & 1.8 & 49 & 240 \\
\hline $52-78$ & 1.495 & 24 & 67 \\
\hline $27-30$ & 2.545 & 81 & 84 \\
\hline $28-29$ & 1.29 & 34 & 175 \\
\hline
\end{tabular}

\subsection{Results and comparison}

The two bundle block adjustment procedures generated the external orientation parameters of the image sets and, subsequently, the clouds of dense points (figure 6). The latter, although elaborated with the same parameters, generated a different amount of points: the Nikon model consists of 6 million points while the Huawei shows more than 14 million points. Both the camera positions and the point clouds (duly thinned for clarity of representation) have been plotted in Matlab environment to compare the two models. Figure 7 shows the result of the mapping of the two models.

A substantial correspondence between the two models can be seen in the right part of the diagram. This match decreases when moving to the left, until the two models become largely shifted in the left bottom side, reaching a maximum value of 2 meters.

Not surprisingly, the first section represents the external area of the cave, where the three GCPs were positioned, while the second one is the inner part of the cave, characterized by a longer and more disturbed distance from the GCPs.

Next, we wanted to verify if this divergence was only related to a simple scale problem. A first registration of the models was then operated to assess this kind of variation. For this reason, the two point clouds were subjected to the Iterative Closest Point (ICP) algorithm using the CloudCompare software (v. 2.6.3). 
This registration procedure allows to best overlap the two clouds by the computation of the Helmert transformation parameters necessary to minimize the distances between their points: one cloud remains as a reference and the other one is transformed until the best fit is found (Troisi et al., 2015). The Huawei cloud has been chosen as reference model as it shows the smallest error value for GCPs and scale constraints. The scale factor is the most interesting outcome among the resulting parameters (one scale factor, three shifts and three rotations) as it turned out to be 0.923 , quite far from 1.
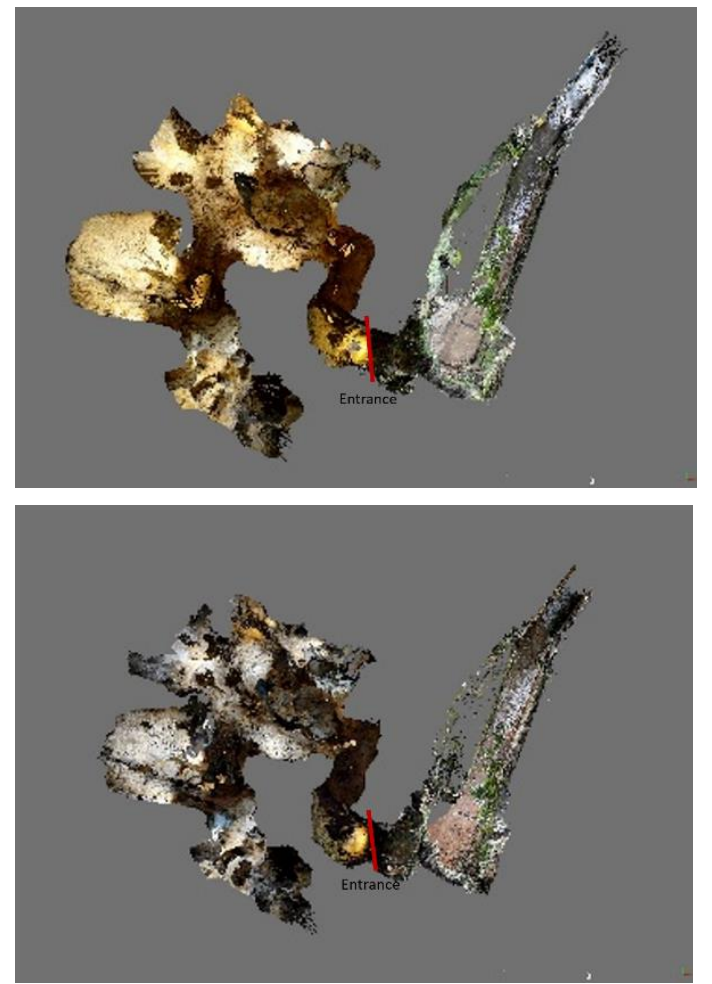

Figure 6. The Nikon (a) and Huawei (b) dense clouds

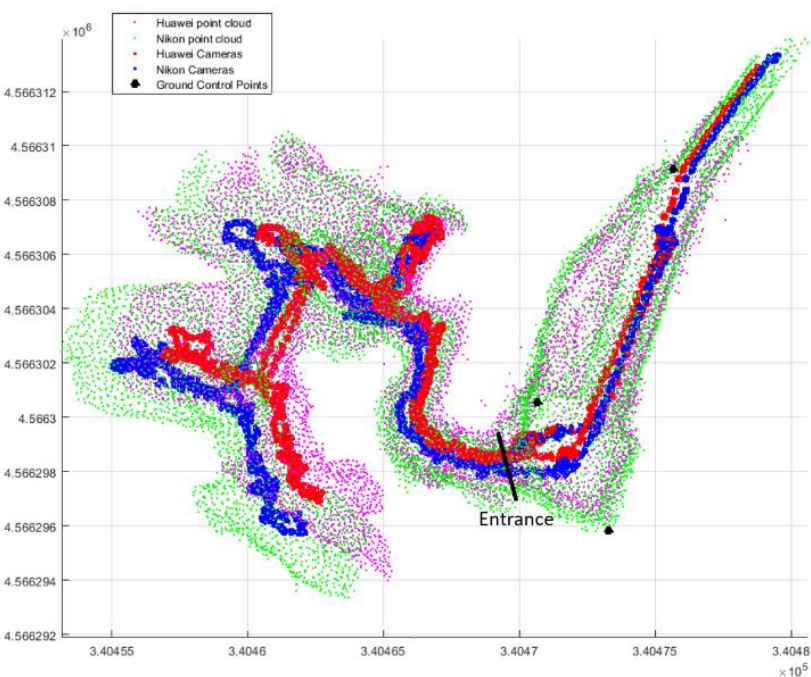

Figure 7. The mapping of the point clouds and relative cameras.

Once registered, the two clouds were compared again, using the Cloud Compare $\mathrm{M} 3 \mathrm{C} 2$ plugin. This algorithm calculates the signed distances along the normal direction of the reference model. Figure 8 shows the obtained distances between the registered Nikon and Huawei clouds through the mapping of the associated colored histogram. The results of the statistical analysis of the differences are reported in figure 9 and summarized by the following data:

- mean $=-0.059 \mathrm{~m}$;

- standard deviation $= \pm 0.312 \mathrm{~m}$;

$12.3 \%$ of the distances is greater than $0.5 \mathrm{~m}$ while $2.4 \%$ is over 1 $\mathrm{m}$.

This statistic reveals that a simple Helmert transformation with scale variation is not sufficient to minimize the differences between the two models and that therefore there is an evident anisotropic distortion in the Nikon model.

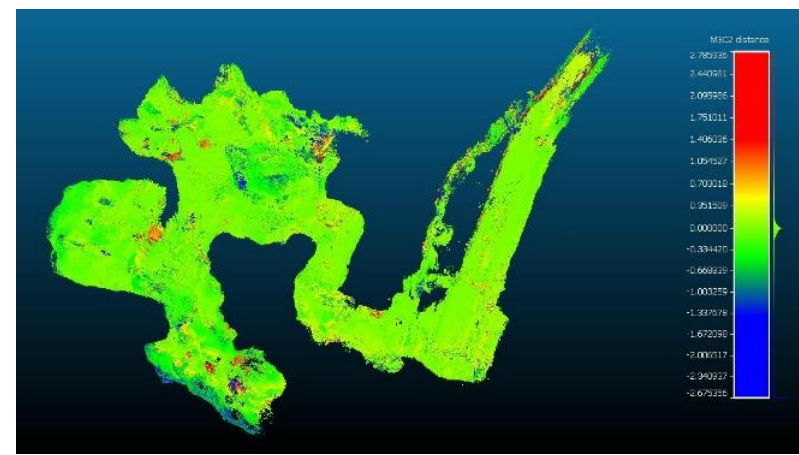

Figure 8 . The coloured distances histogram on the error map.

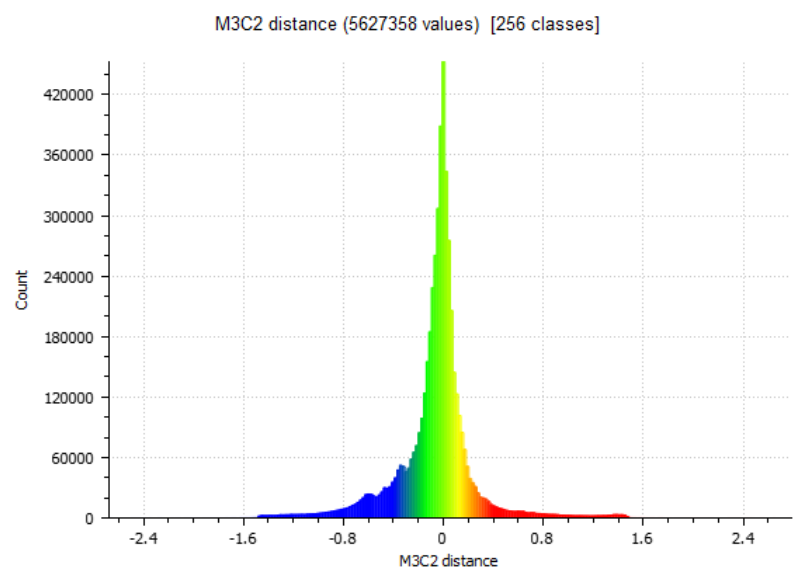

Figure 9. The histogram of the $\mathrm{M} 3 \mathrm{C} 2$ distances between the registered models.

\section{CONCLUSIONS}

This report presents the results of the 3D survey of the Guattari cave, made with the SfM photogrammetric procedure using two different cameras: a Huawei P9 mobile phone and a Nikon D800E camera with a $16 \mathrm{~mm}$ fisheye lens.

Agisoft Metashape 1.5.0 software was used to orient more than 3000 images per model, which have been scaled and georeferenced using both the 3 GCPs placed outside the cave and the four scale constraints. The biggest errors on the GCPs and on the distances shown by the Nikon model might be due to both the lower resolution of the video $(1280 \times 720$ format $)$ and the imperfect determination of the interior orientation parameters obtained by the self-calibration procedure.

On the other hand, the model obtained with the Huawei camera shows very low errors on the GCPs and on the scale constraints. This suggests that when high precision is not required and when expensive equipment cannot be used, even a simple smartphone can be used for georeferencing and modeling a cave of archaeological interest. 


\section{REFERENCES}

Alessandri, L., Baiocchi, V., Del Pizzo, S., Rolfo, M. F., Troisi, S., 2019. Photogrammetric survey with fisheye lens for the characterization of the La Sassa Cave. International Archives of the Photogrammetry, Remote Sensing and Spatial Information Sciences, XLII-2/W9, 25-32, DOI: 10.5194/isprs-archives-XLII2-W9-25-2019

Angelini, M. G., Baiocchi, V., Costantino, D., and Garzia, F., 2017. Scan to BIM for $3 d$ reconstruction of the papal basilica of Saint Francis in Assisi in Italy. Int. Arch. Photogramm. Remote Sens. Spatial Inf. Sci., XLII-5/W1, 47-54, DOI: 10.5194/isprsarchives-XLII-5-W1-47-2017.

Blanc, A.C., Segre, A.G., Cardini, L., 1953. Excursion au Mont Circé, Livret-Guide du IV Congrès Int. INQUA. Istituto Italiano di Paleontologia Umana, Roma.

Blanc, A.C., 1961, Some evidence for the ideologies of early man, in The Social Life of Early Man, ed. Washburn, S.L.. Chicago: Aldine, 119-36

Chikatsu, H., Takahashi, Y., 2009. Comparative evaluation of consumer grade cameras and mobile phone cameras for close range photogrammetry. Proceedings of SPIE - The International Society for Optical Engineering 7447,74470H, DOI: $10.1117 / 12.825746$

Eyre, M., Wetherelt, A., Coggan, J., 2016. Evaluation of automated underground mapping solutions for mining and civil engineering applications. J Appl Remote Sens 10(4):46011. DOI:10.1117/1. JRS.10.046011

Fritsch, D., Syll, M., 2015. Photogrammetric 3D reconstruction using mobile imaging. Proceedings of SPIE - The International Society for Optical Engineering 9411,94110C. DOI: $10.1117 / 12.2083332$

Mandelli, A., Fassi, F., Perfetti, L., Polari, C., 2017. Testing different survey techniques to model architectonic narrow spaces. ISPRS - International Archives of the Photogrammetry, Remote Sensing and Spatial Information Sciences, XLII-2/W5, 505-511. DOI:10.5194/isprs-archives-XLII-2-W5-505-2017

Marra, F., Petronio, C., Ceruleo, P., Di Stefano, G., Florindo, F., Gatta, M., La Rosa, M., Rolfo, M. F., Salari, L., 2018, The archaeological ensemble from Campoverde (Agro Pontino, central Italy): new constraints on the Last Interglacial sea level markers. Scientific Reports, 8, 17837, 1-11. DOI: 10.1038/s41598-018-36111-x

Nocerino, E., Menna, F., \& Remondino, F., 2014: Accuracy of typical photogrammetric networks in cultural heritage $3 \mathrm{D}$ modeling projects. The International Archives of Photogrammetry, Remote Sensing and Spatial Information Sciences, 40(5), 465. DOI: 10.5194/isprsarchives-XL-5-4652014

Nocerino, E., Poiesi, F., Locher, A., Tefera, Y.T., Remondino, F., Chippendale, P., Van Gool, L., 2017. 3D reconstruction with a collaborative approach based on smartphones and a cloudbased server. International Archives of the Photogrammetry, Remote Sensing and Spatial Information Sciences - ISPRS
Archives 42(2W8), pp. 187-194. DOI:10.5194/isprs-archivesXLII-2-W8-187-2017

Perfetti, L., Polari, C., Fassi, F., 2017. Fisheye photogrammetry: Tests and methodologies for the survey of narrow spaces. International Archives of the Photogrammetry, Remote Sensing and Spatial Information Sciences - ISPRS Archives 42(2W3), pp. 639-644, DOI: 10.5194/isprs-archives- XLII-2-W3-573-2017

Sammartano, G., Spanò, A., 2018. Point clouds by SLAM-based mobile mapping systems: accuracy and geometric content validation in multisensor survey and stand-alone acquisition. Applied Geomatics, 10:317-339, DOI: 10.1007/s12518-0180221-7

Schwarcz, H.P., Buhay, W., Grün, R., Stiner, M., Kuhn, S., Miller, G.H., 1991. Absolute dating of sites in coastal Lazio. Quaternaria nova, 1, 51-67.

Stocchi, P., Antonioli, F., Montagna, P., (...), Sciortino, R., Pierre, C., 2017. A stalactite record of four relative sea-level highstands during the Middle Pleistocene Transition. Quaternary Science Reviews, 173, pp. 92-100 DOI: 10.1016/j.quascirev.2017.08.008

Troisi, S., Del Pizzo, S., Gaglione, S., Miccio, A., Testa, R.L., 2015. 3D Models comparison of complex shell in underwater and dry environments. The International Archives of the Photogrammetry, Remote Sensing and Spatial Information Sciences, Volume XL-5/W5, DOI:10.5194/isprsarchives-XL-5W5-215-2015.

Troisi, S., Baiocchi, V., Del Pizzo, S., Giannone, F., 2017. A prompt methodology to georeference complex hypogea environments. International Archives of the Photogrammetry, Remote Sensing and Spatial Information Sciences - ISPRS Archives 42(2W3), pp. 639-644 DOI: 10.5194/isprs-archivesXLII-2-W3-639-2017

White T. and Toth N. 1991, The Question of Ritual Cannibalism at Grotta Guattari, Current Anthropology, 32, 2, 118-138. 